\title{
CONSCIÊNCIA FONOLÓGICA EM SUJEITOS DE BAIXA RENDA, PROCEDENTES DE SALVADOR, NA FAIXA ETÁRIA DE SETE ANOS
}

\section{$\underline{\text { Rhillary Lopes Vieira }}{ }^{1}$; Vera Pedreira dos Santos Pepe ${ }^{2}$}

1. Bolsista Probic/ UEFS, Graduanda em Letras Vernáculas, Universidade Estadual de Feira de Santana, email: rhillaryvieira@hotmail.com

2. Orientadora, Departamento de Letras e Artes, Universidade Estadual de Feira de Santana, email: verapepe2010@gmail.com

PALAVRAS-CHAVE: consciência fonológica; linguística; baixa renda.

\section{INTRODUÇÃO}

Nesta pesquisa, o objetivo geral é traçar o perfil linguístico de crianças de sete anos em tarefas de consciência fonológica e os objetivos específicos são analisar o desempenho de crianças na faixa etária de sete anos em tarefas de consciência fonológica nos níveis da sílaba e do fonema; identificar possíveis estratégias linguísticas utilizadas pelas crianças e elaborar uma escala dos graus de dificuldades das tarefas executadas.

A consciência fonológica representa a capacidade que o indivíduo possui de refletir e manipular as unidades fonológicas da língua (sílabas, unidades intrassilábicas e fonemas) conscientemente (COSTAS, 2012). A literatura especializada faz muita referência à relação da consciência fonológica com aquisição da leitura e escrita, bem como à importância da utilização de atividades de consciência fonológica nesse processo (NUNES et alii, 2009).

Além disso, estudos fazem referência ao impacto de variáveis para o desenvolvimento da consciência fonológica, como o fator socioeconômico (Adams et alii, 2006). Nesse sentido, aponta-se que quanto mais desfavorecido o nível socioeconômico, menos desenvolvida a consciência fonológica.

Dessa forma, é importante que estudos como este sejam desenvolvidos, possibilitando, assim, que professores conheçam mais sobre o tema, pois isso os ajudará a identificar possíveis dificuldades dos seus alunos no processo de aquisição da lectoescrita.

\section{MATERIAIS E MÉTODOS OU METODOLOGIA}

As amostras utilizadas neste estudo são de três crianças de baixa renda na faixa etária de sete anos, alunos de uma creche escola localizada na cidade de Salvador-Ba. 
Os dados são secundários, tendo em vista que já haviam sido coletados para a pesquisa "Funções Executivas e Desenvolvimento Cognitivo em Crianças de Baixa Renda em Savador, Bahia, Brasil.

O CONFIAS- Consciência Fonológica: Instrumento de Avaliação Sequencial (MOOJEN et alii, 2003) foi o instrumento utilizado para a coleta dos dados. Esse instrumento tem por objetivo avaliar a consciência fonológica de forma abrangente e, por isso é dividido em dois níveis: nível da sílaba (S) e nível do fonema (F). O primeiro nível é formado por nove tarefas e o segundo por sete tarefas.

Nesta pesquisa, uma tarefa é considerada consolidada pelo sujeito se o mesmo tiver, no mínimo, um percentual de 75\% de acerto.

\section{RESULTADOS E/OU DISCUSSÕES (ou Análise e Discussão dos Resultados)}

Como é possível ver na Tabela 1, as tarefas mais fáceis e já consolidadas pela maioria dos sujeitos foram: Segmentação e Produção de palavra com sílaba dada (S5), ambas com 83\%, e Identificação de sílaba inicial (S3) 75\% de acerto. A Síntese (S1) foi a terceira tarefa mais fácil com a média de 66,6\% e está prestes a ser consolidada. Produção de rima foi a tarefa com menor percentual de acerto (25\%), e as demais tarefas tiveram uma média entre $40 \%$ e $50 \%$.

Adotando o critério "grau crescente de dificuldade”, a ordem das tarefas foi a seguinte: Segmentação (S2), Produção de palavra com sílaba dada (S5)> Identificação de sílaba inicial (S3)> Síntese (S1)> Identificação de rima (S4), Identificação de sílaba medial (S6)> Exclusão (S8)> Transposição (S9)> Produção de rima (S7).

Tabela1- Desempenho dos Sujeitos 1,2 e 3 no nível da sílaba

\begin{tabular}{l|cccc} 
TAREFAS & SUJEITO & SUJEITO & SUJEITO & MÉDIA \\
& 1 & 2 & 3 & GERAL \\
\hline S1- Síntese & $100 \%$ & $0 \%$ & $100 \%$ & $66,6 \%$ \\
S2- Segmentação & $100 \%$ & $100 \%$ & $50 \%$ & $83,3 \%$ \\
S3- Identificação de sílaba inicial & $100 \%$ & $50 \%$ & $75 \%$ & $75 \%$ \\
S4- Identificação de rima & $75 \%$ & $25 \%$ & $50 \%$ & $50 \%$ \\
S5- Produção de palavra com sílaba dada & $100 \%$ & $100 \%$ & $50 \%$ & $83,3 \%$ \\
S6- Identificação de sílaba medial & 505 & $25 \%$ & $75 \%$ & $50 \%$ \\
S7- Produção de rima & $50 \%$ & $0 \%$ & $25 \%$ & $25 \%$
\end{tabular}




\begin{tabular}{l|cccc|}
\hline S8- Exclusão & $75 \%$ & $12,5 \%$ & $38 \%$ & $41,8 \%$ \\
S9- Transposição & $100 \%$ & $0 \%$ & $25 \%$ & $41,6 \%$ \\
MÉDIA & $83 \%$ & $32,5 \%$ & $53 \%$ & $57,4 \%$ \\
\hline
\end{tabular}

A seguir, os resultados da análise dos dados dos sujeitos no nível do fonema.

A Tabela 2, a seguir, mostra o desempenho dos sujeitos no nível do fonema. Nesse nível, apenas a tarefa Produção de palavra com som dado (F1) já foi consolidada, e essa tarefa foi também a mais fácil com 83,3\% de acerto. Exclusão (F4) e Síntese (F5) estão mais próximas de serem consolidadas, visto que apresentaram as médias de 55,3\% e 50\%, respectivamente. Nas demais tarefas, os sujeitos não apresentaram um bom desempenho no geral. Vale ressaltar que a Transposição (F7) teve uma média de 8,3\%, sendo, assim, a tarefa mais difícil.

A ordem das tarefas no nível do fonema, seguindo o critério das mais fáceis para as mais difíceis, é a seguinte: Produção de palavra com som dado (F1) >Exclusão (F4)> Síntese(F5)> Identificação de fonema final(F3)> Identificação de fonema inicial (F2)> Segmentação (F6)> Transposição (F7).

Tabela 2- Desempenho dos sujeitos 1, 2 e 3 no nível do fonema

TAREFAS

SUjeito SUjeito SUJEITO MÉDiA

$\begin{array}{llll}1 & 2 & 3 & \text { GERAL }\end{array}$

\begin{tabular}{l|llll|}
\hline F1- Produção de palavra com som dado & $100 \%$ & $75 \%$ & $75 \%$ & $83,3 \%$ \\
F2- Identificação de fonema inicial & $100 \%$ & $50 \%$ & $25 \%$ & $28 \%$ \\
F3- Identificação de fonema final & $50 \%$ & $25 \%$ & $25 \%$ & $33 \%$ \\
F4- Exclusão & $100 \%$ & $33 \%$ & $33 \%$ & $55,3 \%$ \\
F5- Síntese & $50 \%$ & $50 \%$ & $50 \%$ & $50 \%$ \\
F6- Segmentação & $50 \%$ & $25 \%$ & $0 \%$ & $25 \%$ \\
F7- Transposição & $0 \%$ & $25 \%$ & $0 \%$ & $8,3 \%$ \\
Média & $67 \%$ & $40 \%$ & $35 \%$ & $40,1 \%$ \\
\hline
\end{tabular}

Fazendo um apanhado geral do nível da sílaba e do nível do fonema, nota-se que os sujeitos tiveram um melhor desempenho no primeiro nível, De qualquer modo, nenhum dos níveis foi consolidado ainda. 
Com relação às estratégias linguísticas utilizadas pelos sujeitos, constatou-se o uso de 14 estratégias, a saber: Repetição da $1^{\mathrm{a}}$ opção, Repetição da $2^{\mathrm{a}}$ opção, Repetição da $3^{\mathrm{a}}$ opção. Associação semântica, Associação fonológica, Silabificação, Repetição do estímulo, Associação fonológica-lexicalização, Repetição da $1^{\text {a }}$ letra, Repetição da última sílaba, Associação fonológica-semântica, Apagamento da $1^{\text {a }}$ sílaba, Silabificação-soletração, Repetição da $1^{\mathrm{a}}$ sílaba. Visando o acerto, os sujeitos utilizam as estratégias quando não sabem a resposta da atividade.

\section{CONSIDERAÇÕES FINAIS (ou Conclusão)}

Fazendo um apanhado geral dos três sujeitos tanto no nível da sílaba quanto no nível do fonema, notou-se que o nível da sílaba foi mais fácil que o nível do fonema. Foram utilizadas estratégias linguísticas em ambos os níveis, como Repetição da $1^{\mathrm{a}}$ opção, Silabificação, Repetição da última sílaba, entre outras.

Os resultados apontam uma escala dos graus de dificuldades das tarefas. No nível da sílaba as mais fáceis foram Segmentação (S2) e Produção de palavra com sílaba dada (S5), enquanto a mais difícil foi Produção de rima (S7). No nível do fonema, a tarefa mais fácil foi produção de palavra que inicia com som dado (F1), já a tarefa mais difícil foi Transposição (F7). Essa escala não necessariamente seguiu a escala de complexidade das tarefas apresentada no teste CONFIAS.

\section{REFERÊNCIAS}

ADAMS, MJ; FOORMAN, BR; LUNDBERG, I; BELER, T. Consciência fonológica em crianças pequenas. Porto alegre: Artmed; 2006.

COSTA, Renata Gomes da: Consciência fonológica em adultos da EJA. Instituto de letras, Salvador-Bahia, 2012. Dissertação de mestrado. UFBA.

MOOJEN, Sônia et al. Consciência fonológica: Instrumentos de avaliação sequencial. São Paulo: casa do Psicólogo, 2003.

Nunes, C. et al. Consciência fonológica e o processo de aprendizagem de leitura e escrita: implicações teóricas para o embasamento da prática fonoaudiológica, 2009. Disponível em: http://www.scielo.br/pdf/rcefac/v11n2/v11n2a05.pdf. Acesso em: 02 de ago de 2017. 